\title{
Monitoring Of Hand-Arm Vibration
}

\author{
Shamsul Akmar Ab Aziz \\ Department of Mechanical and Material Engineering, Faculty of Engineering and Built Environment, Universiti \\ Kebangsaan Malaysia (UKM), 43600 Bangi, Selangor, Malaysia \\ Science and Technology Research Institute for Defence (STRIDE), Ministry of Defence, Taman Bukit Mewah Fasa \\ 9, 43000 Kajang, Selangor, Malaysia
}

\section{Mohd Zaki Nuawi}

Department of Mechanical and Material Engineering, Faculty of Engineering and Built Environment, Universiti Kebangsaan Malaysia (UKM), 43600 Bangi, Selangor, Malaysia

\author{
Mohd Jailani Mohd Nor \\ Universiti Teknikal Malaysia Melaka (UTeM), Hang Tuah Jaya, 76100 Durian Tunggal, Melaka, Malaysia
}

(Received 14 October 2014; accepted 30 September 2015)

This paper aims to describe the development of a statistical analysis method called the integrated kurtosis-based algorithm for a $Z$-notch filter (I-kaz) Vibro for monitoring hand-arm vibration (HAV) in Malaysian Army (MA) three-tonne truck steering wheels. HAV from the steering wheel was measured using a single axis piezoelectric accelerometer that was connected to a Brüel \& Kjær Type 3649 vibration analyser. The raw acceleration data was integrated to obtain velocity data and reintegrated to obtain displacement data. The data was analysed using I-kaz Vibro to determine the vibration values in relation to varying speeds of the truck and to determine the degree of data scattering for three-axial raw data signals for acceleration, velocity, and displacement in the $x-, y$-, and $z$-axes, respectively. Based on the results obtained, HAV experienced by the drivers can be presented using daily vibration exposure $A(8)$, the I-kaz Vibro coefficient $\left(Z_{v}^{\infty}\right)$, and the I-kaz Vibro display. For the developed model validation, predicted and measured values of $A(8)$ were compared and a relatively good agreement was obtained between them. The low average relative error $(4.78 \%)$ for the developed equation model demonstrated that I-kaz Vibro is very effective in monitoring HAV in steering wheels.

\section{NOMENCLATURE}

$a_{h i} \quad$ Tangential rms acceleration measured for the $i^{\text {th }}$ onethird octave band

$a_{h w z}$ Frequency weighted acceleration

$A(8)$ Daily vibration exposure

$f_{s} \quad$ Sampling frequency

$f_{\max }$ Maximum frequency

GVW Gross vehicle weight

HAV Hand-arm vibration

$K \quad$ Kurtosis

$K_{A} \quad$ Kurtosis for acceleration value

$K_{D} \quad$ Kurtosis for displacement value

$K_{V} \quad$ Kurtosis for velocity value

$R^{2} \quad$ Coefficient of correlation

$w_{h i} \quad$ Frequency weighting factor

$x_{i}^{A} \quad$ Data for the $i^{\text {th }}$-sample of time for acceleration value

$x_{i}^{D} \quad$ Data for the $i^{\text {th }}$-sample of time for displacement value

$x_{i}^{V} \quad$ Data for the $i^{\text {th }}$-sample of time for velocity value

$z_{v}^{\infty} \quad$ I-kaz vibro coefficient

$\sigma^{2} \quad$ Variance

$\sigma_{A}^{2} \quad$ Variance for acceleration value

$\sigma_{D}^{2} \quad$ Variance for displacement value

$\sigma_{V}^{2} \quad$ Variance for velocity value
$\sigma_{A} \quad$ Standard deviation for acceleration value

$\sigma_{D} \quad$ Standard deviation for displacement value

$\sigma_{V} \quad$ Standard deviation for velocity value

$\mu_{A} \quad$ Mean for acceleration value

$\mu_{D} \quad$ Mean for displacement value

$\mu_{V} \quad$ Mean for velocity value

\section{INTRODUCTION}

Vibrations from the engine are transmitted to the steering wheel through the steering rod and can be felt by the driver's hands and arms. In the design of vehicle steering systems, there is no steering damper that can absorb vibration from steering wheels or parts inside in the steering system that can attenuate the vibration. While vibration in steering wheels can give drivers tactile feedback on the conditions of the vehicle and road, it may affect the driver's judgments of ride comfort. ${ }^{1}$ Hence, one of the many critical areas of noise, vibration, and harshness (NVH) is the discomfort felt from vibration in the steering wheel as a driver drives his/or her vehicle. ${ }^{2}$ Tests were performed on Malaysian Army (MA) three-tonne trucks (shown in Fig. 1), which are the most widely used military vehicle in Malaysia. Table 1 shows the basic specifications for this truck.

In our previous studies, an integrated kurtosis-based algo- 


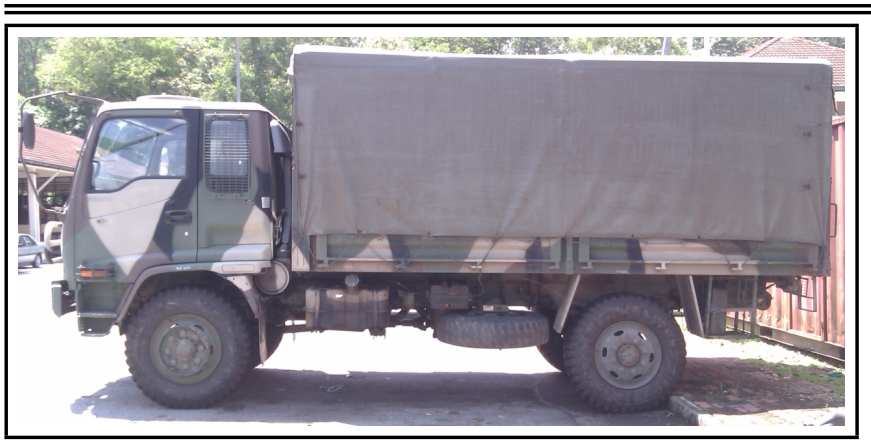

Figure 1. A Malaysian Army (MA) three-tonne truck.

rithm for $Z$-notch filter (I-kaz) was used for analysing noise and vibration in the driver cabin of MA three-tonne trucks. Aziz et al. ${ }^{4}$ produced a regression model for predicting noise exposure in the driver's compartment, while Aziz et al. ${ }^{5}$ studied on whole body vibration (WBV) exposure from the vehicle seat. This paper aims to describe a new statistical analysis method, I-kaz Vibro, for monitoring hand-arm vibration (HAV) in MA three-tonne truck steering wheels. The scope of this paper begins with time domain integration of acceleration raw data to produce a velocity and displacement time discrete continuous raw data. The acceleration, velocity, and displacement raw data are divided to the $x-, y$-, and $z$-axes, respectively to produce a $3 \mathrm{D}$ graphical representation, known as the I-kaz display. The proposed I-kaz Vibro method is used to produce a value known as the I-kaz Vibro coefficient $\left(Z_{v}^{\infty}\right)$, which represents the HAV experienced by the driver from the steering wheel, in particular whether the value is large or small. Therefore, HAV levels acting on the driver's hands and arms can be predicted by determining $Z_{v}^{\infty}$. HAV exposure to drivers based on change in vehicle speed will affect the value of the measured vibration signal. ${ }^{6}$ Finally, a new mathematical model will be developed based on the correlation relationships between the truck speed, HAV, and $Z_{v}^{\infty}$. This mathematical model can be used to predict HAV in MA three-tonne truck steering wheels.

\section{SELECTION OF DATA FOR ANALYSIS OF HAV IN STEERING WHEELS}

Past studies using the integration method mostly employed time domain acceleration. ${ }^{6,7}$ For example, the study by Tang ${ }^{8}$ on a simple supported beam with two boundary conditions and a stepped beam with one boundary condition was conducted by using a combination of a dynamic stiffness matrix and time domain integration for determining the transient response of the beams. Calculation and comparison of two different beams proved that this method could be used effectively for analysis of vibration, which the beams were subjected to. Although it is common practice (e.g., in measuring earthquake ground motion) to integrate accelerations to obtain velocities and again to obtain displacements, this practice is fraught with major pitfalls. This point is particularly true for causal integration schemes that would be required for continuous monitoring setups. ${ }^{9}$ Earthquake studies using earthquake data records obtained from the U.S. Department of Geology contain spectral response and time series data for acceleration, velocity, and
Table 1. Specifications for the MA three-tonne trucks. ${ }^{3}$

\begin{tabular}{|l|l|}
\hline GVW & $10000 \mathrm{~kg}$ \\
\hline Engine type & $\begin{array}{l}\text { HICOM 6HH1 4 Cycle, 6 Cylinder in-line, } \\
\text { direct injection, water-cooled, Diesel engine }\end{array}$ \\
\hline Displacement & $8266 \mathrm{cc}$ \\
\hline Horsepower & $147 \mathrm{~kW}(200 \mathrm{PS})$ @ $2850 \mathrm{rpm}$ \\
\hline Torque & $500 \mathrm{Nm}(51 \mathrm{kgm})$ @ $1700 \mathrm{rpm}$ \\
\hline Wheelbase & $3800 \mathrm{~mm}$ \\
\hline Power to weight ratio & $15.9 \mathrm{~kW} /$ ton \\
\hline Steering type & Re-circulated ball, with internal power assisted \\
\hline
\end{tabular}

displacement. The recorded earthquake signals use the same scale and processing method so that comparison with previous data can be performed without any problems. ${ }^{7}$

Based on ISO 5349-1 recommendations, ${ }^{10}$ the most important quantity used to describe the magnitude of the vibration transmitted to the driver's hands is root mean square (rms) frequency-weighted acceleration. Engine idle vibration that occurs at the steering wheel can be simulated using the amplitude modulated acceleration time history, with the sinusoidal carrier reported to provide the best reproduction. ${ }^{4,5}$ The process of detecting defects and problem solving in engineering has been performed using time and frequency domain analytical methods. Despite the frequency domain using dynamic response data source equal to the time domain, the amount of useful raw data is remarkably reduced through transformation and is more often used because it is easier to do the calculation and data processing. However, the damping of a structure cannot be estimated using frequency domain analysis. This is due the non-linearity of the visco-elastic material, which is difficult to model in the frequency domain. ${ }^{11}$ To overcome the shortcomings of the frequency domain and to produce better results, time domain analysis can be used as an alternative to analyse the acceleration of vibration. ${ }^{12}$

The vibration level in the steering wheel depends on various factors, which include the type and condition of the road surface, and the dynamic nature of tyres, engine, suspension system design and steering mechanism. ${ }^{13}$ These factors will produce different patterns of vibration, which are transferred to the vehicle through the front and rear axle, and steering rod. In addition, driver response to HAV depends on various factors such as wave amplitude ${ }^{14}$ and the size of the frequency band in the vibrating steering wheel. ${ }^{15}$ The way in which steering wheel vibration affects comfort is complex and depends on the magnitude, frequency and direction of vibration; the location of contact with the hands; and the posture of the hands. ${ }^{1}$ Dynamic instability of the vehicle's engine, steering rods and other mechanical systems is a key factor in the increase in magnitude of steering vibration. ${ }^{16}$ The studies conducted by Adewusi et al., ${ }^{17}$ Aldien et al., ${ }^{18}$ and Marcotte et al. ${ }^{19}$ on the steering wheel handle have shown that the effects of HAV on the human hand-arm system depends on various factors, such as handle size, hand-handle contact force, grip forces, handarm posture, and direction and magnitude of vibration.

The vibration entering the hand contains contributions from all three orthogonal directions $(x, y$ and $z) .{ }^{10}$ The study by Dewangan and Tewari ${ }^{20}$ on hand tractors found that the rms vibration acceleration was highest in the $x$-axis followed by the 
$z$ - and $y$-axes, with maximum vibration values of $5.52,8.07$ and $5.27 \mathrm{~ms}^{-2}$ at frequency of $31.5 \mathrm{~Hz}$ during transportation, rota-tilling and rota-puddling respectively. The study by Yoo et al. $^{2}$ on Korean made passenger cars found that the rms vibration acceleration was more dominant in the $x$-axis for asphalt and bumpy roads. However, for different road types, such as Belgian, block and cobbled roads, the rms vibration acceleration was more dominant in the $y$-axis. Eaton ${ }^{21}$ found that for various types of buses driven on city streets with the same speed, the dominant vibration was in the $x$-axis. Goglia et al. ${ }^{22}$ found that vibration transmitted to the steering wheel of small four-wheel drive tractors is more dominant in the $z$ axis for idle and full load operating conditions. In the idle condition, the highest mean value of frequency-weighted acceleration was $3.47 \mathrm{~ms}^{-2}$ for the $z$-axis, followed by $x$ - and $y$-axes with 2.14 and $2.00 \mathrm{~ms}^{-2}$, respectively. In the full load, the $z$-axis was also the most dominant with an average value of frequency weighted acceleration of $16.4 \mathrm{~ms}^{-2}$, followed by the $y$ - and $x$-axes with $6.85 \mathrm{~ms}^{-2}$ and $3.85 \mathrm{~ms}^{-2}$, respectively. The study by Aziz et al. ${ }^{23}$ on MA three-tonne trucks on paved roads without carrying loads using a Brüel \& Kjær Type 4447 human vibration analyser found that the $z$-axis was the most dominant, with the highest rms frequency-weighted vibration acceleration values as compared to the $x$ - and $y$-axes. Based on these studies, it can be concluded that the type of vehicle, type of road, and idle / load condition determine which is the most dominant HAV axis.

Thus, they proposed that the use of a one-axis accelerometer mounted on the $z$-axis of the steering wheel could be used to replace a triaxial accelerometer to measure HAV for this type of vehicle. Similarly, Shibata et al. ${ }^{24}$ developed a single axis vibration test system for the measurement of a biodynamic response of a human hand-arm system. Giacomin and $\mathrm{Woo}^{25}$ also used a single axis accelerometer to study HAV in the $z$ axis of the steering wheel. The $z$-axis is perpendicular ${ }^{2}$ or in tangential direction to the $x-y$ plane, and is positive in the direction towards the steering column. As only a single axis of vibration could be reproduced experimentally in the present study, the tangential direction was selected as the most representative and useful in light of possible future developments in automotive steering technology. ${ }^{25}$ Table 2 shows a summary of various operating / tests conditions that have been performed by different investigators on various types of vehicles. This shows that there are many factors that determine the dominant axis for measuring and monitoring HAV of the hands and arms of the driver.

\section{I-KAZ VIBRO STATISTICAL ANALYSIS}

Statistical parameters derived from the time domain signals, such as the root mean square value, kurtosis, crest factor, skewness, peak value, and signal-to-noise ratio are most widely used to detect a defect. ${ }^{26}$ I-kaz Vibro was developed based on the concept of data scattering about a data centroid with the display classified according to inferential statistics. It is used to model data patterns that contain elements of randomness and draw inferences from a larger population. ${ }^{27}$ Therefore, a significant correlation between the data obtained with the sample
Table 2. A summary of the various operating / test conditions used by different investigators.

\begin{tabular}{|c|c|c|c|c|c|c|}
\hline \multirow{2}{*}{$\begin{array}{c}\text { Investi- } \\
\text { gators }\end{array}$} & \multirow{2}{*}{$\begin{array}{c}\text { Tested } \\
\text { vehi- } \\
\text { cles }\end{array}$} & \multirow{2}{*}{\multicolumn{2}{|c|}{$\begin{array}{l}\text { Operating / test } \\
\text { conditions }\end{array}$}} & \multicolumn{3}{|c|}{$\begin{array}{c}\text { Several of vibration } \\
\text { acceleration data }\left(\mathrm{ms}^{-2}\right)\end{array}$} \\
\hline & & & & $x$-axis & $y$-axis & $z$-axis \\
\hline \multirow{9}{*}{$\begin{array}{c}\text { Dewan- } \\
\text { gan } \\
\text { and } \\
\text { Tewari }^{20}\end{array}$} & \multirow{9}{*}{$\begin{array}{l}\text { Hand } \\
\text { tractors }\end{array}$} & \multirow{9}{*}{$\begin{array}{c}\text { Opera- } \\
\text { tional } \\
\text { mode }\end{array}$} & \multirow{3}{*}{$\begin{array}{c}\text { Trans- } \\
\text { porta- } \\
\text { tion }\end{array}$} & 5.45 & 2.33 & 3.29 \\
\hline & & & & 6.69 & 2.8 & 5.1 \\
\hline & & & & 7.88 & 3.36 & 5.42 \\
\hline & & & \multirow{3}{*}{$\begin{array}{l}\text { Rota- } \\
\text { tilling }\end{array}$} & 5.62 & 2.39 & 2.64 \\
\hline & & & & 5.87 & 2.63 & 2.92 \\
\hline & & & & 6.26 & 2.92 & 3.46 \\
\hline & & & \multirow{3}{*}{$\begin{array}{c}\text { Rota- } \\
\text { puddling }\end{array}$} & 3.83 & 1.79 & 2.76 \\
\hline & & & & 4.23 & 2.01 & 3.05 \\
\hline & & & & 4.69 & 2.32 & 3.34 \\
\hline \multirow{10}{*}{$\begin{array}{l}\text { Yoo } \\
\text { et al. }^{2}\end{array}$} & \multirow{10}{*}{$\begin{array}{c}\text { Korean } \\
\text { made } \\
\text { passen- } \\
\text { ger } \\
\text { cars } \\
\text { (Car B) }\end{array}$} & \multirow{10}{*}{$\begin{array}{l}\text { Types } \\
\text { of } \\
\text { road }\end{array}$} & Asphalt & 0.297 & 0.268 & 0.229 \\
\hline & & & road & 0.338 & 0.287 & 0.281 \\
\hline & & & Bumpy & 3.707 & 3.142 & 4.041 \\
\hline & & & road & 9.318 & 5.567 & 8.563 \\
\hline & & & \multirow{3}{*}{$\begin{array}{l}\text { Belgian } \\
\text { road }\end{array}$} & 1.604 & 3.291 & 1.308 \\
\hline & & & & 2.894 & 5.597 & 2.585 \\
\hline & & & & 4.484 & 6.34 & 4.04 \\
\hline & & & Block & 2.162 & 2.413 & 2.02 \\
\hline & & & road & 2.17 & 2.262 & 2.06 \\
\hline & & & $\begin{array}{c}\text { Cobbled } \\
\text { road }\end{array}$ & 4.589 & 8.115 & 4.067 \\
\hline \multirow{10}{*}{ Eaton $^{21}$} & \multirow{10}{*}{ Buses } & \multirow{10}{*}{$\begin{array}{l}\text { Types } \\
\text { of } \\
\text { buses }\end{array}$} & Trolley & 1.27 & 0.98 & 0.6 \\
\hline & & & Iromey & 1.06 & 0.75 & 0.42 \\
\hline & & & High & 0.83 & 0.48 & 0.49 \\
\hline & & & floor & 0.8 & 0.5 & 0.55 \\
\hline & & & Low & 1.47 & 0.66 & 0.94 \\
\hline & & & floor & 1.19 & 0.49 & 0.64 \\
\hline & & & Highway & 0.82 & 0.44 & 0.22 \\
\hline & & & coach & 0.74 & 0.46 & 0.32 \\
\hline & & & Articu- & 0.62 & 0.44 & 0.25 \\
\hline & & & lated & 0.76 & 0.56 & 0.35 \\
\hline \multirow{10}{*}{$\begin{array}{l}\text { Goglia } \\
\text { et al. }\end{array}$} & \multirow{10}{*}{$\begin{array}{l}\text { Small } \\
\text { four- } \\
\text { wheel } \\
\text { drive } \\
\text { tractor }\end{array}$} & \multirow{10}{*}{$\begin{array}{c}\text { Oper- } \\
\text { ating } \\
\text { condi- } \\
\text { tions }\end{array}$} & \multirow{5}{*}{ Idling } & 1.85 & 1.08 & 3.47 \\
\hline & & & & 2.08 & 2.00 & 3.26 \\
\hline & & & & 2.14 & 1.94 & 3.43 \\
\hline & & & & 1.96 & 1.53 & 3.41 \\
\hline & & & & 1.94 & 1.76 & 3.30 \\
\hline & & & & 3.85 & 6.85 & 16.40 \\
\hline & & & & 3.68 & 6.73 & 15.50 \\
\hline & & & Full & 3.38 & 6.78 & 17.60 \\
\hline & & & load & 3.68 & 6.71 & 15.50 \\
\hline & & & & 3.45 & 6.51 & 16.10 \\
\hline & & & 40 & 0.420 & 0.315 & 0.492 \\
\hline & & & $\mathrm{kmh}^{-1}$ & 0.354 & 0.233 & 0.376 \\
\hline & & & & 0.955 & 0.826 & 1.222 \\
\hline & Three- & & $\begin{array}{c}80 \\
\mathrm{kmh}^{-1}\end{array}$ & 0.487 & 0.402 & 0.587 \\
\hline $\begin{array}{c}\text { AZIZ } \\
\text { et al } 23\end{array}$ & tonne & sneeds & & 0.484 & 0.363 & 0.528 \\
\hline & trucks & & & 0.764 & 0.468 & 0.949 \\
\hline & & & 90 & 0.792 & 0.559 & 1.069 \\
\hline & & & $\mathrm{kmh}^{-1}$ & 0.733 & 0.665 & 1.055 \\
\hline & & & & 0.520 & 0.411 & 0.744 \\
\hline
\end{tabular}

can be identified. This paper presents a statistical method, Ikaz Vibro, based on integration of time discrete continuous acceleration raw data. As the algorithm is defined only with the time history of acceleration measured at limited locations, it does not require any information on actual dynamic responses other than acceleration. ${ }^{12}$

The Sampling Theorem states that perfect signal analysis is possible when half of the sampling frequency $\left(f_{s}\right)$, also called the Nyquist frequency, is greater than the maximum fre- 
quency $\left(f_{\max }\right)$ of the sampled signal. ${ }^{28}$ Figliola $\&$ Beasly ${ }^{29}$ and Daubechies ${ }^{30}$ also suggested that the Nyquist number must be 2 or greater in order to avoid the content of the sampling signal to be misinterpreted. The maximum frequency span is described as follows:

$$
f_{\max }=\frac{f_{s}}{2} .
$$

I-kaz Vibro is different from the original I-kaz developed by Nuawi et al. ${ }^{27}$ I-kaz has also been used by researchers to analyse various types of signals and has been expanded from the original I-kaz ${ }^{27}$ to I-kaz $3 \mathrm{D},{ }^{4,28} \mathrm{I}-\mathrm{kaz}$ Hybrid, ${ }^{29,30}$ and I-kaz Multilevel $^{31,32}$ to suit different types of experiments and collected raw data. In the original I-kaz, a dynamic signal in the time domain is decomposed into three frequency ranges: $x$ axis, low frequency (LF) ranges between $0-0.25 f_{\max } ; y$-axis, high frequency (HF) ranges between $0.25 f_{\max }-0.5 f_{\max }$; and $z$-axis, very high frequency (VF) ranges between $0.5 f_{\max }-$ $f_{\max } \cdot{ }^{27}$ The selection of $0.25 f_{\max }$ and $0.5 f_{\max }$ implies the concept of a second order of the Daubechies in the signal decomposition process. ${ }^{30}$ In comparison, in I-kaz Vibro, a vibration signal in the time domain is decomposed into three signals, which are the acceleration, velocity, and displacement in the $x-, y$-, and $z$-axes respectively. The kurtosis $(K)$ and standard deviation $(\sigma)$ values for each axis will be determined to calculate $Z_{v}^{\infty}$. In order to measure the scattering of the data distribution, the variance $\left(\sigma^{2}\right)$ for each axis, which are $\sigma_{A}^{2}, \sigma_{V}^{2}$, and $\sigma_{D}^{2}$, is calculated as shown in Eq. (2). The variance determines the average magnitude deviation of instantaneous points with respect to the mean value. The variance for $N$ data points is mathematically defined as:

$$
\begin{aligned}
\sigma_{A}^{2} & =\frac{\sum_{i=1}^{N}\left(x_{i}^{A}-\mu_{A}\right)^{2}}{N} ; \\
\sigma_{V}^{2} & =\frac{\sum_{i=1}^{N}\left(x_{i}^{V}-\mu_{V}\right)^{2}}{N} ; \\
\sigma_{D}^{2} & =\frac{\sum_{i=1}^{N}\left(x_{i}^{D}-\mu_{D}\right)^{2}}{N} .
\end{aligned}
$$

I-kaz Vibro was developed based on the concept of data scattering about its centroid. The $Z_{v}^{\infty}$ coefficient can be written in terms of the $\sigma^{2}$ as follows:

$$
\begin{aligned}
& Z_{v}^{\infty}=\sqrt{\left(\sigma_{A}^{2}\right)^{2}+\left(\sigma_{V}^{2}\right)^{2}+\left(\sigma_{D}^{2}\right)^{2}} ; \\
& Z_{v}^{\infty}=\sqrt{\frac{\sum_{i=1}^{N}\left(x_{i}^{A}-\mu_{A}\right)^{4}}{N^{2}}+\frac{\sum_{i=1}^{N}\left(x_{i}^{V}-\mu_{V}\right)^{4}}{N^{2}}+\frac{\sum_{i=1}^{N}\left(x_{i}^{D}-\mu_{D}\right)^{4}}{N^{2}}} ;
\end{aligned}
$$

where $x_{i}^{A}, x_{i}^{V}$, and $x_{i}^{D}$, and $\mu_{a}, \mu_{v}$, and $\mu_{d}$ are the data for the $i^{\text {th }}$-sample of time and means of each axis respectively.

Kurtosis shows the distribution of the data with a value of zero for $K$ indicating that the distribution is $100 \%$ normal. Positive $K$ indicates a higher form of distribution and vice versa for negative $K{ }^{36} \mathrm{~K}$ is usually used to detect any changes in signal amplitude. It is a global signal measurement that is sensitive to the spikiness of the data. For discrete data, $K$ is defined as:

$$
K=\frac{1}{n \sigma^{4}} \sum_{i=1}^{n}\left(x_{i}-\bar{x}\right)^{4} .
$$

I-kaz Vibro is used to measure the spread of data distribution by calculating the distance of each centroid signal from the raw data. This technique produces a graphical representation of the frequency distribution of the measured signal in each axis in addition to producing a value for $Z_{v}^{\infty}$. The concept of data dispersion and diffusion space can be observed in the Ikaz Vibro display with higher values corresponding to a wider dispersion of data. This process will produce a 3D graphic representation of time domain signals measuring the acceleration, velocity, and displacement on the frequency distribution of $x$-, $y$-, and $z$-axes respectively.

The final I-kaz Vibro equation to compute $Z_{v}^{\infty}$ is written in terms of kurtosis and standard deviation is as follows:

$$
z_{v}^{\infty}=\frac{1}{N} \sqrt{K_{A} \sigma_{A}^{4}+K_{V} \sigma_{V}^{4}+K_{D} \sigma_{D}^{4}} ;
$$

where $K_{A}$ and $\sigma_{A}$ are the kurtosis and standard deviation, respectively for acceleration in the $x$-axis; $K_{V}$ and $\sigma_{V}$ are the kurtosis and standard deviation, respectively for velocity in the $y$-axis; and $K_{D}$ and $\sigma_{D}$ are the kurtosis and standard deviation, respectively for displacement in the $z$-axis. The flow chart for the I-kaz Vibro algorithm is shown in Fig. 2.

\section{EXPERIMENTAL PROCEDURE}

The experimental layout used in this study is shown in Fig. 3. A single axis Brüel \& Kjær piezoelectric accelerometer was placed on the top left side of the steering wheel. It was connected to a Brüel \& Kjær Type 3649 vibration analyser and controlled by the PULSE Version 8 software, which logged 800 times/s in units of $\mathrm{ms}^{-2}$ for a duration of $180 \mathrm{~s}$. The accelerometer location on the steering wheel during the measurement was as recommended in ISO 5349-2.37 The tangential direction acceleration time histories were measured under five conditions: idle and moving at speeds of $20,40,60$, and $80 \mathrm{kmh}^{-1}$. The idle speed reading was taken when the vehicle engine was switched on and no forward gear was engaged. Speed selection was based on the MA truck engine's capacity and the maximum speed limit allowed by the Road Transport Act 1987 for heavy vehicles on Malaysian highways. ${ }^{38}$ Five different speeds are chosen so that the small changes that occur in each set of recorded data can be observed and analysed by using I-kaz Vibro. The measurement for each truck speed was repeated at least three times to ensure that the data is accurate and reliable for further analysis.

Based on the findings obtained in Aziz et al., ${ }^{23} \mathrm{HAV}$ acceleration was measured in the tangential direction to the steering wheel. The time histories of acceleration values were obtained from the one-third octave band analysis in the frequency range of up to $100 \mathrm{~Hz}$, which is the frequency range of vibration in MA three-tonne truck steering wheels. While the single axis accelerometer does not differentiate the rotational and translational components of the steering acceleration, ${ }^{39}$ based on the findings in Goglia et al. ${ }^{22}$ and Aziz et al., ${ }^{23}$ approximation was made in this study to associate the $z$-axis acceleration time history as the dominant axis to monitor HAV for this type of vehicle. The values of tangential acceleration on the steering wheel were calculated using the following equations after the 


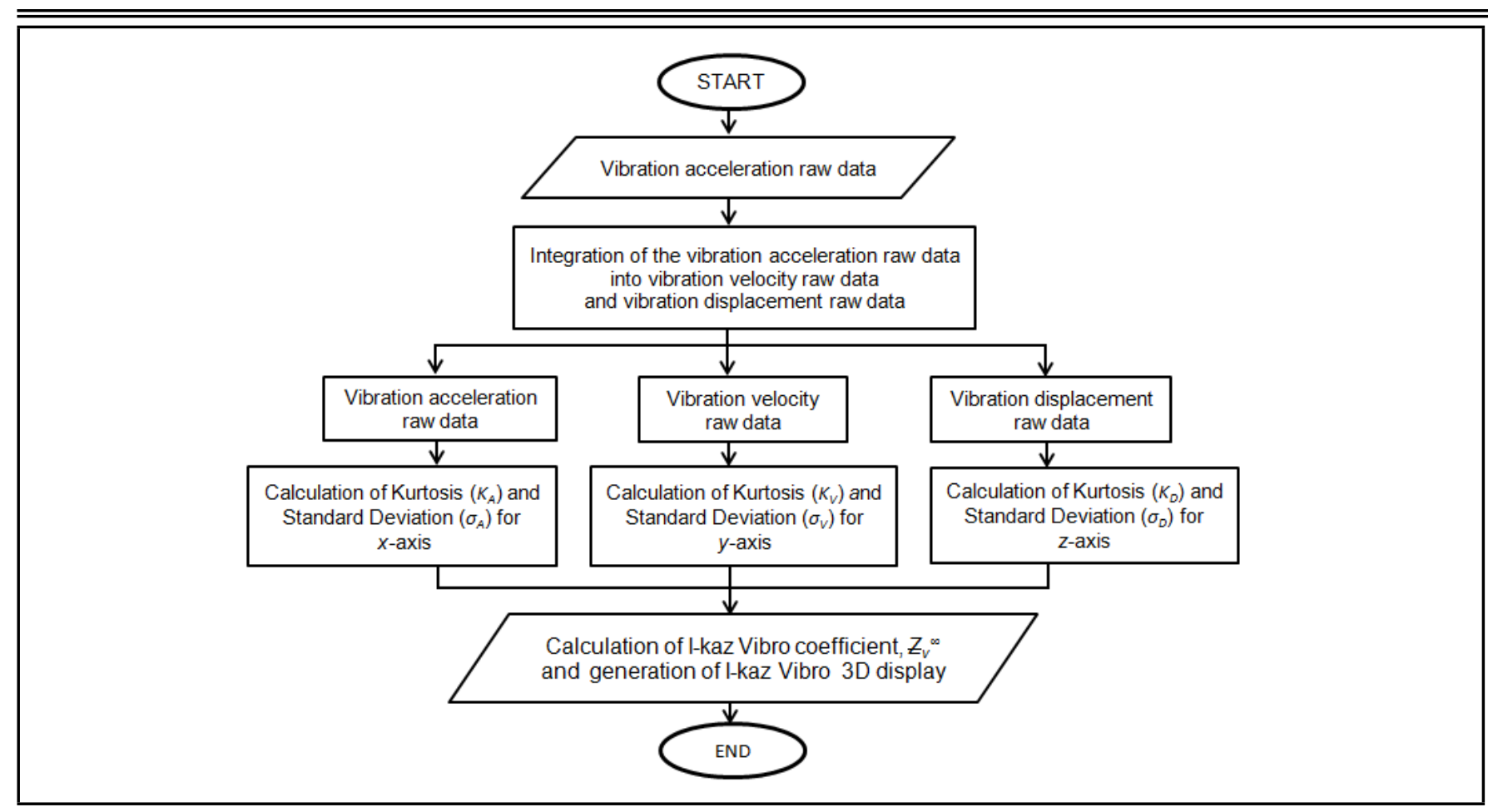

Figure 2. Flowchart of the I-kaz Vibro algorithm.

signal was digitally filtered by the frequency weighting function $w_{h i}$. The rms frequency weighted acceleration $\left(a_{h w z}\right)$ was calculated as follows:

$$
a_{h w z}=\sqrt{\sum_{i}\left(w_{h i} a_{h i}\right)^{2}}
$$

where $w_{h i}$ is the frequency weighting factor and $a_{h i}$ is the tangential rms acceleration measured for the $i^{\text {th }}$ one-third octave band. The $w_{h i}$ weighting was used in measuring and reporting hand-arm exposures for the purpose of quantifying HAV effects and the risk of injury over the full frequency range covered by the one-third octave bands from 6.3 to $1250 \mathrm{~Hz}$, as defined in ISO 5349-2. ${ }^{37}$

The daily vibration exposure in terms of 8-h energy equivalent was derived from the vibration total value $a_{h w z}$. In order to facilitate comparisons between daily exposures of different durations, the daily vibration exposures were expressed in terms of 8 -h energy equivalent frequency-weighted vibration total value, ${ }^{40}$ as shown in the following equation:

$$
A(8)=a_{h w z} \sqrt{\frac{T}{T_{0}}} ;
$$

where $T$ is the total daily duration of exposure in s to the exposure $a_{h w z}$ and $T_{0}$ is the reference duration of $8 \mathrm{~h}(28800 \mathrm{~s})$.

Before the test, the MA drivers were asked to adjust the side mirrors and seat to have a comfortable driving posture. The drivers were also required to remove any accessories they were wearing on their hands and arms such as watches, bracelets, and rings. As hand-arm posture, hand-steering contact, ${ }^{17}$ and grip $^{16,17}$ forces are known to affect the transmission of vibration to the hand-arm system, the drivers were asked to maintain them by using both hands.

\section{RESULTS AND DISCUSSION}

\subsection{Analysis of the Time Domain Data}

The $A(8)$ and $Z_{v}^{\infty}$ values for HAV for the various vehicle speeds are tabulated in Table 3 . It is observed that the $A(8)$ increased with increasing vehicle speed, which indicates that the truck experienced higher vibration. ${ }^{6}$ This resulted in a higher amount of vibration being transmitted through the steering wheel and felt by the driver. The highest value of $A(8)$ of $4.39 \mathrm{~ms}^{-2}$ was obtained at a speed of $80 \mathrm{kmh}^{-1}$. This value exceeded the exposure action value (EAV) stipulated by EU Directive $2002 / 44 / \mathrm{EC}^{41}$ which is $2.5 \mathrm{~ms}^{-2}$. EAV is the daily amount of vibration exposure that employers are required to take action on in order to control exposure. This was followed by speeds of 60,40 , and $20 \mathrm{kmh}^{-1}$, with $A(8)_{\text {avg }}$ values of $2.73,2.13$ and $1.66 \mathrm{~ms}^{-2}$, respectively. The idle condition $(0 \mathrm{~km} / \mathrm{h})$ had the lowest $A(8)_{\text {avg }}$ value of $0.82 \mathrm{~ms}^{-2}$. This finding is consistent with the observation in Aziz et al. ${ }^{23}$ for the same truck and road surface. In addition, the study by Dewangan and Tewari ${ }^{20}$ on a hand tractor that was conducted in a different operational mode, also showed similar results and trends. The study by Yoo et al. ${ }^{2}$ on Korean-made passenger cars was conducted on the same type of road surface and showed that steering wheel vibration increased with increasing vehicle speed for asphalt, bumpy and Belgian road surface types, but not for block road surface type.

HAV has various characteristics at certain conditions of steering wheel vibration. By using I-kaz Vibro, the signals could be used to generate I-kaz Vibro displays that show the values of $Z_{v}^{\infty}$ (Fig. 4). The different dispersions based on the different vehicle speeds show the levels of HAV vibration experienced by the driver, with larger dispersions indicating higher levels of HAV. Therefore, HAV monitoring for the 


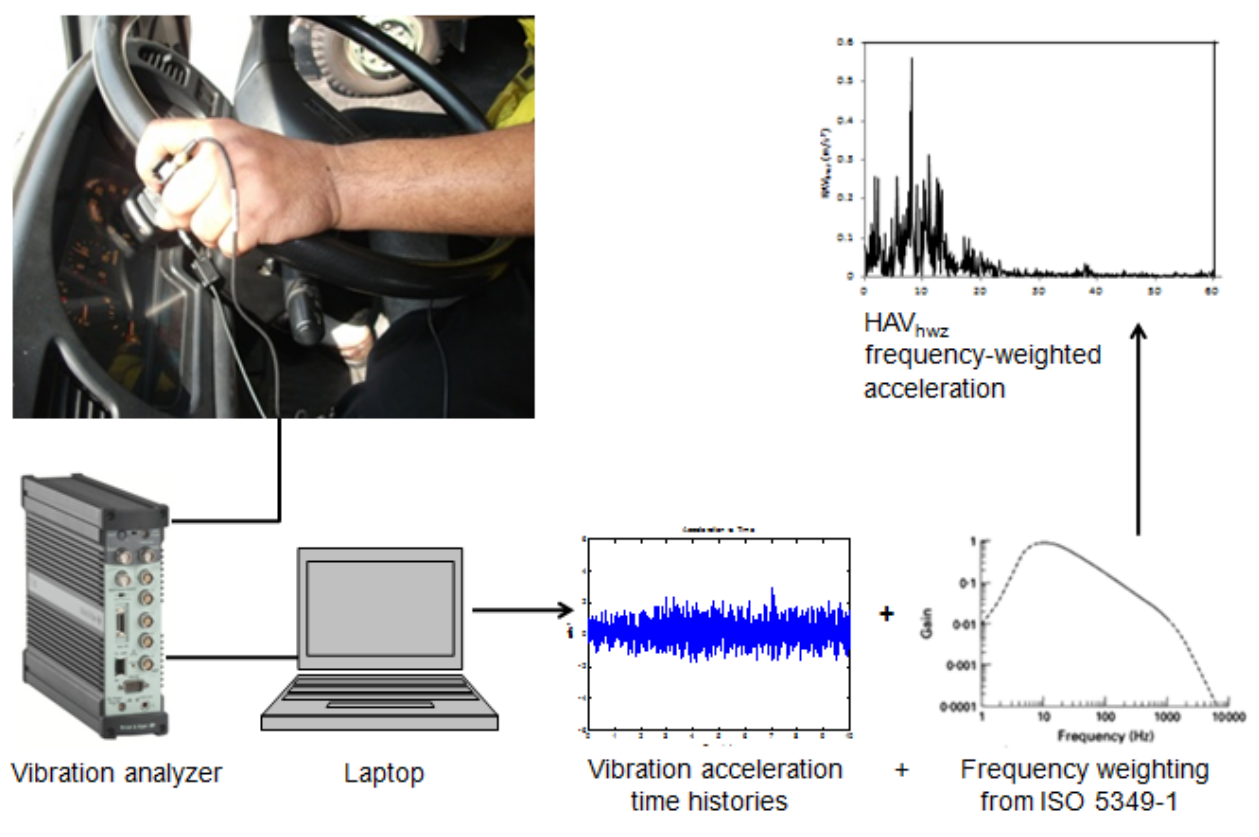

Figure 3. The experimental layout for monitoring HAV in MA three-tonne truck steering wheels.

Table 3. $A(8)$ and $Z_{v}^{\infty}$ values for various vehicle speeds.

\begin{tabular}{|c|c|c|c|c|}
\hline $\begin{array}{c}\text { Vehicle speed } \\
\left(\mathrm{kmh}^{-1}\right)\end{array}$ & $\begin{array}{c}\text { Engine } \\
\text { rotation (rpm) }\end{array}$ & $\begin{array}{c}A(8) \\
\left(\mathrm{ms}^{-2}\right)\end{array}$ & $\begin{array}{l}A(8)_{\mathrm{avg}} \\
\left(\mathrm{ms}^{-2}\right)\end{array}$ & $Z_{v}^{\infty}$ \\
\hline \multirow{3}{*}{0} & \multirow{3}{*}{700} & 0.73 & \multirow{3}{*}{0.82} & $3.74 \times 10^{-5}$ \\
\hline & & 0.82 & & $4.10 \times 10^{-5}$ \\
\hline & & 0.91 & & $5.47 \times 10^{-5}$ \\
\hline \multirow{3}{*}{20} & \multirow{3}{*}{1300} & 1.58 & \multirow{3}{*}{1.66} & $1.30 \times 10^{-4}$ \\
\hline & & 1.74 & & $1.89 \times 10^{-4}$ \\
\hline & & 1.67 & & $1.63 \times 10^{-4}$ \\
\hline \multirow{3}{*}{40} & \multirow{3}{*}{1600} & 2.05 & \multirow{3}{*}{2.13} & $2.03 \times 10^{-4}$ \\
\hline & & 2.18 & & $2.40 \times 10^{-4}$ \\
\hline & & 2.17 & & $2.14 \times 10^{-4}$ \\
\hline \multirow{3}{*}{60} & \multirow{3}{*}{1800} & 2.77 & \multirow{3}{*}{2.73} & $3.05 \times 10^{-4}$ \\
\hline & & 2.78 & & $3.20 \times 10^{-4}$ \\
\hline & & 2.63 & & $2.99 \times 10^{-4}$ \\
\hline \multirow{3}{*}{80} & \multirow{3}{*}{2100} & 4.39 & \multirow{3}{*}{3.93} & $4.70 \times 10^{-4}$ \\
\hline & & 3.98 & & $4.55 \times 10^{-4}$ \\
\hline & & 3.41 & & $3.82 \times 10^{-4}$ \\
\hline
\end{tabular}

driver can be done using the I-kaz Vibro displays. As shown in Fig. 3, increasing values of $A(8)$ with increasing vehicle speed results in an increasing dispersion and values of $Z_{v}^{\infty}$. The highest value of $z_{v}^{\infty}$ at $4.70 \times 10^{-4}$ was obtained for a speed of $80 \mathrm{kmh}^{-1}$. This was followed by speeds of 60,40 , and $20 \mathrm{kmh}^{-1}$ with $Z_{v}^{\infty}$ values of $3.2 \times 10^{-4}, 2.40 \times 10^{-4}$ and $1.89 \times 10^{-4}$, respectively. The idle condition gave the lowest $Z_{v}^{\infty}$ value of $3.74 \times 10^{-5}$. Higher values of $Z_{v}^{\infty}$ indicated that higher values of $A(8)$ were being applied to the driver's hands and arms. In addition, this finding was strongly supported by the observation of the space of scattering of the Ikaz Vibro displays. The data for higher $A(8)$ values distributed further from the mean showed higher scattering. On the other hand, the data for lower $A(8)$ values distributed closer to the mean. This graphical representations show that a bigger space of scatterings indicate that the values of $Z_{v}^{\infty}$ and $A(8)$ are getting higher. The differences in the results of $A(8)$ at varying vehicle speeds are very significant. Further investigation of
HAV applied to the MA driver's hands and arms can be performed easily in condition monitoring by using this statistical analysis.

Figure 5 shows $10 \mathrm{~s}$ segments extracted from the original tangential acceleration time histories, and integrated to obtain velocity and displacement time histories segments. The captured HAV time histories for speeds of 0,40 , and $80 \mathrm{kmh}^{-1}$ were then analysed in the time domain. All of the signals were sampled at 800 samples/s for $10 \mathrm{~s}$. Thus, a time series of 8000 data points was obtained. It is observed that the highest speed of $80 \mathrm{kmh}^{-1}$ contributed to the highest HAV acceleration, velocity and displacement, followed by the medium speed of $40 \mathrm{kmh}^{-1}$. The lowest vehicle speed, which was in the idle condition, gave the lowest HAV acceleration, velocity, and displacement.

\subsection{Mathematical Model for Predicting HAV}

To achieve the objective of this paper, $A(8)$ was plotted against $Z_{v}^{\infty}$, as shown in Fig. 6. A curve fit method with linear polynomial regression was used to plot the graphs. Each data point represents the $A(8)$ and $Z_{v}^{\infty}$ values from Table 3 . From the graph, it was found that $A(8)$ is linearly proportional to $Z_{v}^{\infty}$, with a high coefficient of correlation $R^{2}(98.8 \%)$. The correlation between $A(8)$ and $Z_{v}^{\infty}$ can thus be represented using the following equation:

$$
A(8)=7849\left(Z_{v}^{\infty}\right)+0.421 .
$$

By using this mathematical model, HAV from a steering wheel can be easily predicted from the calculation of the value for $Z_{v}^{\infty}$. The developed equation and $R^{2}$ value demonstrate that I-kaz Vibro is a suitable alternative method for HAV monitoring. In addition, the $p$-value was calculated to determine the level of significance between changes of $A(8)$ and $Z_{v}^{\infty}$ using Microsoft Excel. It was found that the $p$-value is 


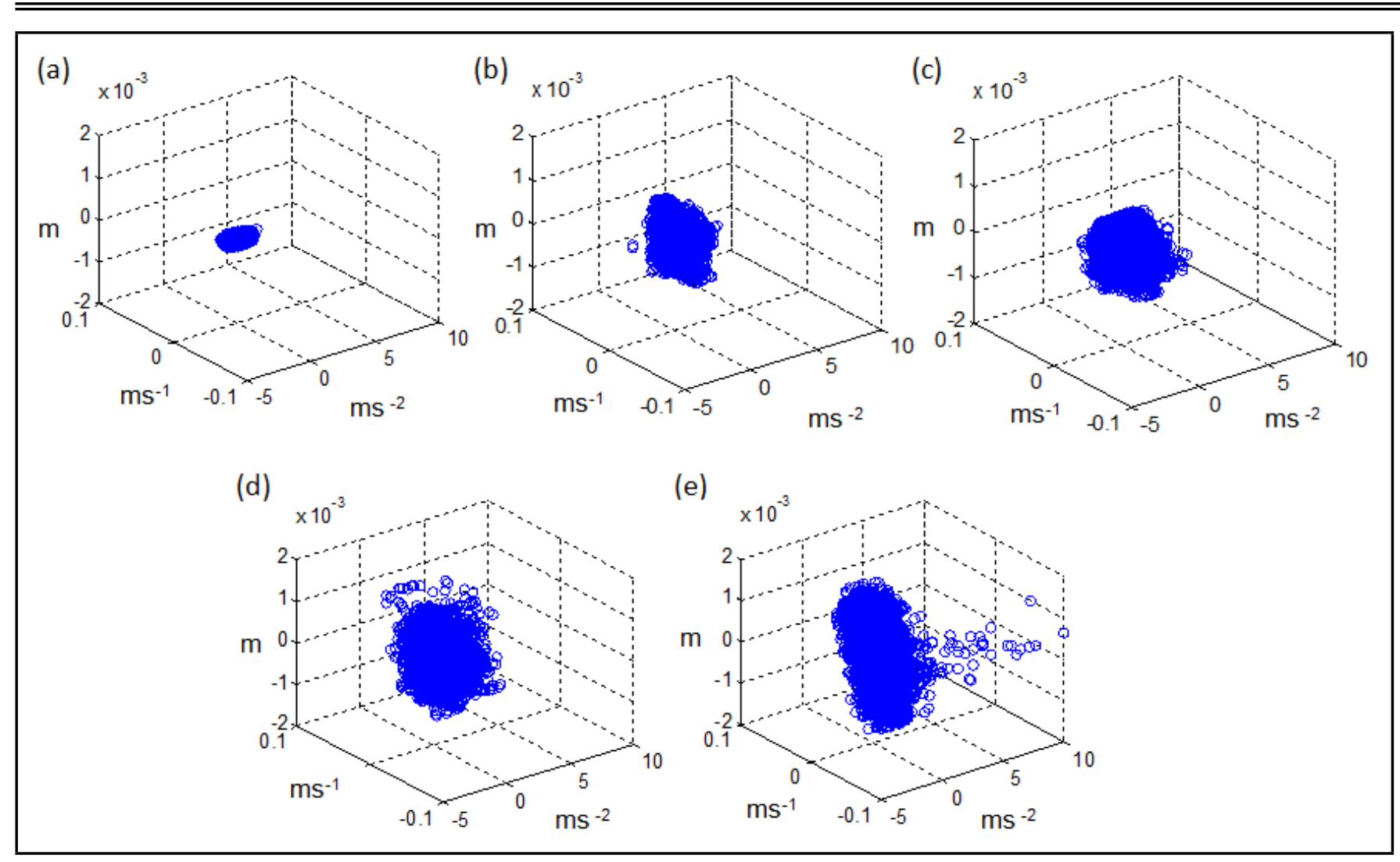

Figure 4. I-kaz Vibro displays for different vehicle speeds: (a) idle, $Z_{v}^{\infty}=3.74 \times 10^{-5}$, (b) $20 \mathrm{kmh}^{-1}, Z_{v}^{\infty}=1.89 \times 10^{-4}$, (c) $40 \mathrm{kmh}^{-1}, Z_{v}^{\infty}=$ $2.40 \times 10^{-4}$, (d) $60 \mathrm{kmh}^{-1}, Z_{v}^{\infty}=3.20 \times 10^{-4}$, and (e) $80 \mathrm{kmh}^{-1}, Z_{v}^{\infty}=4.70 \times 10^{-4}$.

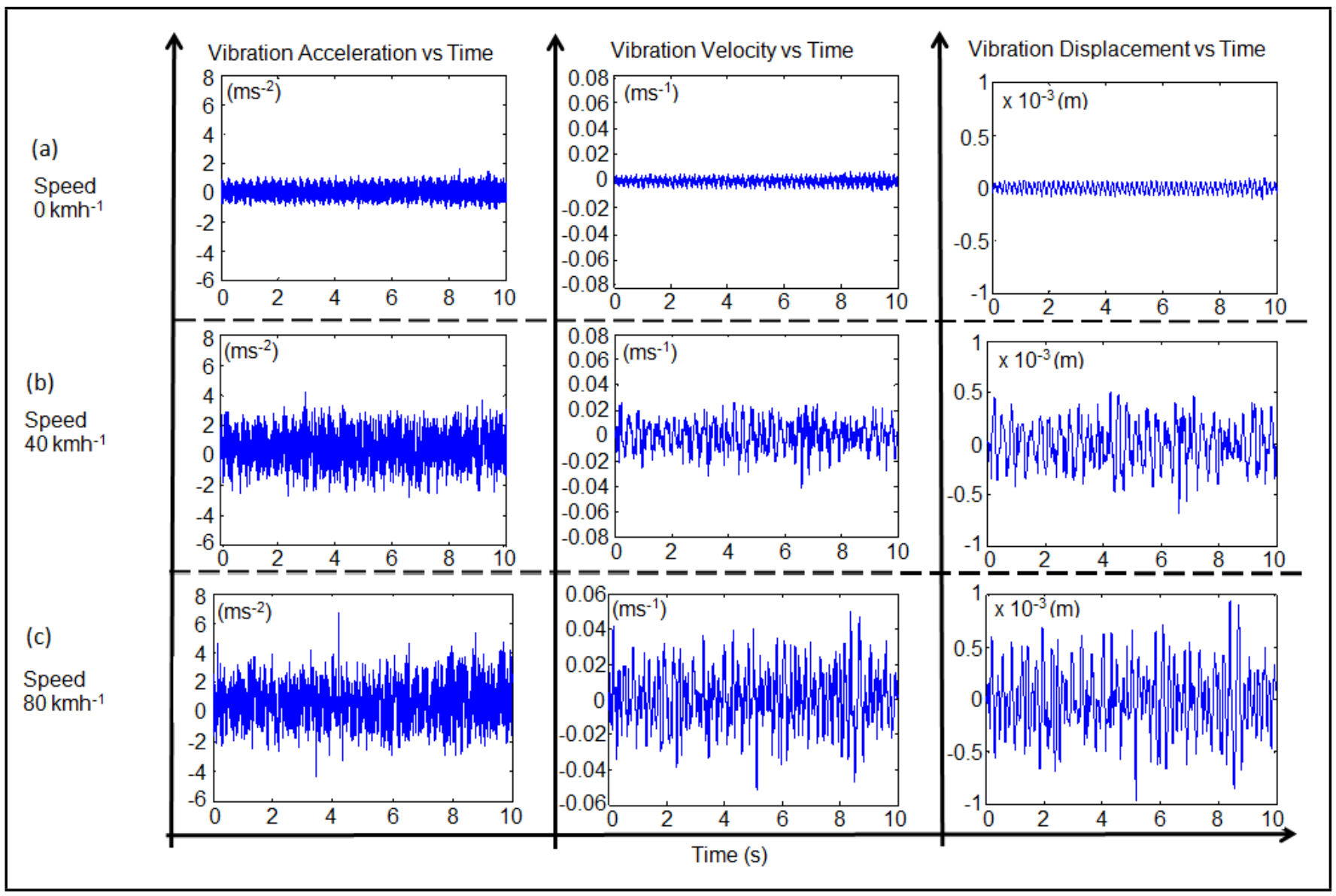

Figure 5. Tangential direction time histories of the steering wheel for vibration acceleration, velocity, and displacement at vehicle speeds of (a) 0 , (b) 40 , and (c) $80 \mathrm{kmh}^{-1}$. 


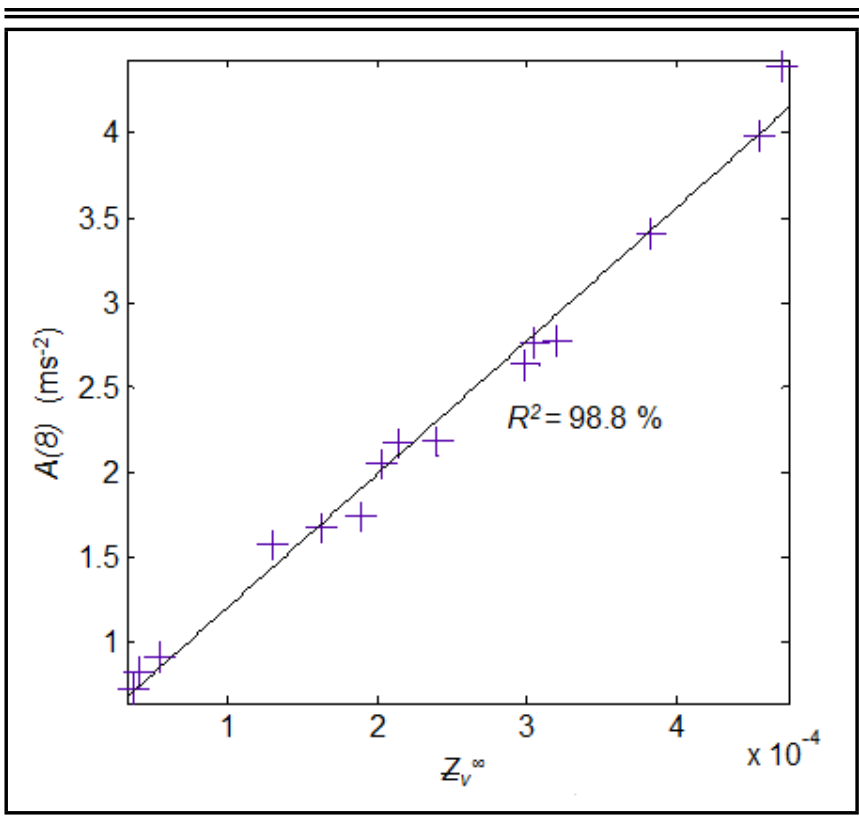

Figure 6. The linear regression between $A(8)$ and $Z_{v}^{\infty}$.

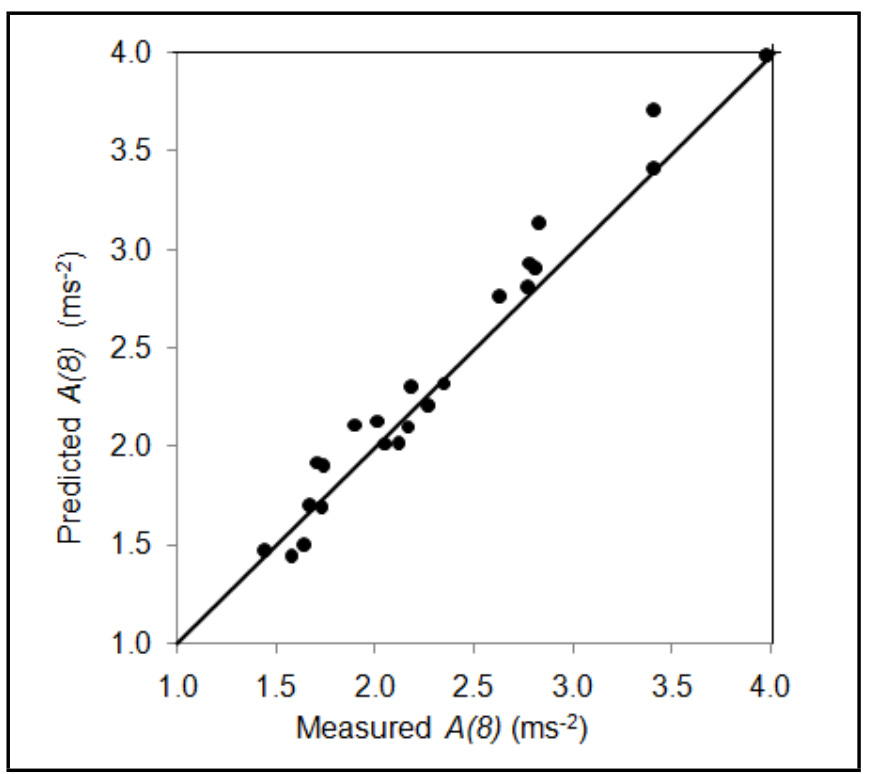

Figure 7. A comparison between the predicted and measured $A(8)$ values.

$6.72 \times 10^{-14}<0.05$ (significance level, $\alpha=0.05$ ), indicating that the changes of $A(8)$ values is significant with the changes of $Z_{v}^{\infty}$ values. These results are significant with the changes of space scatterings of the I-kaz Vibro display based on changes of $A(8)$ values (Fig. 4).

\subsection{Model Validation}

In order to test the accuracy of the I-kaz Vibro method proposed in this study, 32 datasets for $A(8)$ from different threetonne trucks were tested. This was conducted to evaluate the capability of I-kaz Vibro and the developed regression models to predict the HAV exposure on the driver's steering wheel. The relative errors between the predicted and measured $A(8)$ values were then calculated using Eq. (10). The measured and predicted values of HAV exposure and the relative errors for
Table 4. A comparison of the predicted and measured $A(8)$.

\begin{tabular}{||c|c|c|c|c||}
\hline No. & $Z_{v}^{\infty}$ & $\begin{array}{c}\text { Predicted } \\
(8)\left(\mathrm{ms}^{-2}\right)\end{array}$ & $\begin{array}{c}\text { Measured } \\
A(8)\left(\mathrm{ms}^{-2}\right)\end{array}$ & $\begin{array}{c}\text { Relative } \\
\text { error }(\%)\end{array}$ \\
\hline 1 & $3.74 \times 10^{-5}$ & 0.71 & 0.73 & 2.12 \\
\hline 2 & $4.10 \times 10^{-5}$ & 0.74 & 0.82 & 9.43 \\
\hline 3 & $5.47 \times 10^{-5}$ & 0.85 & 0.91 & 6.57 \\
\hline 4 & $1.30 \times 10^{-4}$ & 1.45 & 1.58 & 8.54 \\
\hline 5 & $1.89 \times 10^{-4}$ & 1.91 & 1.74 & 9.51 \\
\hline 6 & $1.63 \times 10^{-4}$ & 1.70 & 1.67 & 2.05 \\
\hline 7 & $2.03 \times 10^{-4}$ & 2.01 & 2.05 & 1.73 \\
\hline 8 & $2.40 \times 10^{-4}$ & 2.31 & 2.18 & 5.9 \\
\hline 9 & $2.14 \times 10^{-4}$ & 2.1 & 2.17 & 3.21 \\
\hline 10 & $3.05 \times 10^{-4}$ & 2.82 & 2.77 & 1.67 \\
\hline 11 & $3.20 \times 10^{-4}$ & 2.93 & 2.78 & 5.49 \\
\hline 12 & $2.99 \times 10^{-4}$ & 2.77 & 2.63 & 5.21 \\
\hline 13 & $4.70 \times 10^{-4}$ & 4.11 & 4.39 & 6.32 \\
\hline 14 & $4.55 \times 10^{-4}$ & 3.99 & 3.98 & 0.26 \\
\hline 15 & $3.82 \times 10^{-4}$ & 3.42 & 3.41 & 0.23 \\
\hline 16 & $1.98 \times 10^{-5}$ & 0.58 & 0.59 & 2.26 \\
\hline 17 & $6.42 \times 10^{-5}$ & 0.92 & 0.94 & 1.61 \\
\hline 18 & $4.19 \times 10^{-4}$ & 3.71 & 3.41 & 8.76 \\
\hline 19 & $3.46 \times 10^{-4}$ & 3.14 & 2.83 & 10.87 \\
\hline 20 & $2.42 \times 10^{-4}$ & 2.32 & 2.35 & 1.26 \\
\hline 21 & $4.60 \times 10^{-4}$ & 4.03 & 4.02 & 0.23 \\
\hline 22 & $3.17 \times 10^{-4}$ & 2.91 & 2.81 & 3.57 \\
\hline 23 & $2.18 \times 10^{-4}$ & 2.13 & 2.01 & 5.91 \\
\hline 24 & $2.28 \times 10^{-4}$ & 2.21 & 2.27 & 2.51 \\
\hline 25 & $1.38 \times 10^{-4}$ & 1.50 & 1.64 & 8.28 \\
\hline 27 & $1.78 \times 10^{-5}$ & 0.56 & 0.55 & 2.01 \\
\hline 28 & $2.15 \times 10^{-4}$ & 2.11 & 1.90 & 11.02 \\
\hline 29 & $2.04 \times 10^{-4}$ & 2.02 & 2.12 & 4.78 \\
\hline 30 & $1.91 \times 10^{-4}$ & 1.92 & 1.71 & 12.27 \\
\hline 31 & $1.34 \times 10^{-4}$ & 1.47 & 2.44 & 2.16 \\
\hline 32 & $1.62 \times 10^{-4}$ & 1.69 & 4.78 \\
\hline & & & Average relative error & \\
\hline
\end{tabular}

the data sets are shown in Table 4.

Relative error $=$

$$
\frac{\mathrm{HAV}_{h w z}(\text { measured })-\mathrm{HAV}_{h w z}(\text { predicted })}{\mathrm{HAV}_{h w z}(\text { measured })} \times 100 \text {. }
$$

It is observed that the predicted $A(8)$ values were very close to the measured $A(8)$ values. The average relative error was $4.78 \%$, which is considered to be within the practically acceptable relative error limits of $10 \% .{ }^{42}$ Figure 7 shows the scatter diagrams of the predicted versus measured $A(8)$ values for the 32 datasets of HAV data. It is observed that the graph fits very well, and the correlations between the predicted and measured values follow the $45^{\circ}$ line very closely.

\section{CONCLUSIONS}

This study has demonstrated that I-kaz Vibro is a suitable statistical analysis method for prediction and monitoring of HAV for MA three-tonne truck steering wheels. Higher values of $A(8)$ will display larger scatterings in the I-kaz Vibro display and result in higher values of $Z_{v}^{\infty}$. From the analysis, $Z_{v}^{\infty}$ was found to be linearly related to $A(8)$ and vehicle speed, with a low average relative error of $4.78 \%$. This indicates that the developed model and estimated results are very accurate and encouraging to be applied for the driver's HAV 
exposure monitoring. The reason for this is that the I-kaz Vibro method was developed based on standard deviation and kurtosis, which are used for detection of changing of HAV because of their sensitivity to changing of amplitude. Apart from MA truck steering wheels, the method can also be used to monitor HAV exposure from other vehicle steering wheels such as buses, cars, vans and tractors. In the future, this method is expected to be applied in the automotive industry to monitor HAV exposure to the driver. I-kaz Vibro can also be used as a new statistical method to analyse other types of vibration, such as from earthquakes, machines, bridges and buildings.

\section{REFERENCES}

1 Morioka, M. and Griffin, M. J. Equivalent comfort contours for vertical vibration of steering wheels: effect of vibration magnitude, grip force, and hand position, Applied Ergonomics, 40, 817-825, (2009). http://dx.doi.org/10.1016/j.apergo.2008.06.001

2 Yoo, W. S., Na, S. D., and Kim, M. S. Relationship between subjective and objective evaluations of steering wheel vibration, Journal of Mechanical Science and Technology, 25 (7), 1695-1701, (2011). http://dx.doi.org/10.1007/s12206-011-0420-1

3 DEFTECH, Technical specification truck 3 ton $4 \times 4$ Hicom Handalan II, (2007).

4 Aziz, S. A. A., Nuawi, M. Z., Nor, M. J. M., and Daruis, D. D. I. New regression models for predicting noise exposure in the driver's compartment of Malaysian army threetonne trucks, Advances in Mechanical Engineering, Article ID 616093, (2014). http://dx.doi.org/10.1155/2014/616093

5 Aziz, S. A. A., Nuawi, M. Z., and Nor, M. J. M. Predicting whole-body vibration (WBV) exposure of Malaysian Army three-tonne truck drivers using Integrated Kurtosis-Based Algorithm for Z-Notch Filter Technique 3D (I-kaz 3D), International Journal of Industrial Ergonomics, 52, 59-68, (2016). http://dx.doi.org/10.1016/j.ergon.2015.08.008

6 Aziz, S. A. A., Nuawi, M. Z., Nor, M. J. M., and Daruis, D. D. I. Study of noise, vibration and harshness (NVH) for Malaysian Army (MA) 3-tonne trucks, Applied Mechanics and Materials, 471, 74-80, (2014). http://dx.doi.org/10.4028/www.scientific.net/amm.471.74

7 Ismail Ibrahim, K. M. H. and Ibrahim, T. E. Effect of historical earthquakes on pre-stressed anchor tie back diaphragm wall and on near-by building, HBRC Journal, 9 (1), 60-67, (2013). http://dx.doi.org/10.1016/j.hbrcj.2013.02.008

8 Tang, B. Combined dynamic stiffness matrix and precise time integration method for transient forced vibration response analysis of beams, Journal of Sound and Vibration, 309, 868-876, (2008). http://dx.doi.org/10.1016/j.jsv.2007.07.075

9 Smyth, A. and Wu, M. Multi-rate Kalman filtering for the data fusion of displacement and acceleration response measurements in dynamic system monitoring, Mechanical Systems and Signal Processing, 21, 706-723, (2007). http://dx.doi.org/10.1016/j.ymssp.2006.03.005

10 ISO 5349-1, Mechanical vibration-measurement and evaluation of human exposure to hand-transmitted vibration-Part 1: general requirements, ISO, Geneva, (2001). http://dx.doi.org/10.3403/02534966

11 Breukelman, B., Haskett, T., Gamble, S., and Irwin, P. Analysis and model techniques for determining dynamic behaviour of civil structures with various damping systems, Proceedings of CTBUH 6th World Congress, (2001). http://dx.doi.org/10.4324/noe0415232418.ch43

12 Kang, J. S., Park, S.-K., Shin, S., and Lee, H. S. Structural system identification in time domain using measured acceleration, Journal of Sound and Vibration, 288, 215-234, (2005). http://dx.doi.org/10.1016/j.jsv.2005.01.041

13 Giacomin, J. and Fustes, F. Subjective equivalence of steering wheel vibration and sound, International Journal of Industrial Ergonomics, 35, 517-526, (2005). http://dx.doi.org/10.1016/j.ergon.2004.11.004

14 Ajovalasit, M. and Giacomin, J. Human subjective response to steering wheel vibration caused by diesel engine idle, Proceedings of the Institution of Mechanical Engineers, Part D: Journal of Automobile Engineering, 219, 499-510, (2005). http://dx.doi.org/10.1243/095440705x11167

15 Woo, Y. and Giacomin, J. The role of the scale and the frequency bandwidth of steering wheel vibration on road surface recognition, Proceedings of the 8th International Symposium on Advance Vehicle Control, AVEC'06, Taipei, Taiwan, (2006).

16 Tewari, V. K. and Dewangan, K. N. Effect of vibration isolators in reduction of work stress during field operation of hand tractor, Biosystems Engineering, 103, 146-158, (2009). http://dx.doi.org/10.1016/j.biosystemseng.2009.03.002

17 Adewusi, S. A., Rakheja, S., Marcotte, P., and Boutin, J. Vibration transmissibility characteristics of the human hand-arm system under different postures, hand forces and excitation levels, Journal of Sound and Vibration, 329, 2953-2971, (2010). http://dx.doi.org/10.1016/j.jsv.2010.02.001

18 Aldien, Y., Marcotte, P., Rakheja, S., and Boileau, P.-É. Influence of hand forces and handle size on power absorption of the human hand-arm exposed to $z_{h}$-axis vibration, Journal of Sound and Vibration, 290, 1015-1039, (2006). http://dx.doi.org/10.1016/j.jsv.2005.05.005

19 Marcotte, P., Aldien, Y., Boileau, P.-É., Rakheja, S., and Boutin, J. Effect of handle size and hand-handle contact force on the biodynamic response of the hand-arm system under $z_{h}$-axis vibration, Journal of Sound and Vibration, 283, 1071-1091, (2005). http://dx.doi.org/10.1016/j.jsv.2004.06.007 
${ }^{20}$ Dewangan, K. N. and Tewari, V. K. Characteristics of hand-transmitted vibration of a hand tractor used in three operational modes, International Journal of Industrial Ergonomics, 39 (1), 239-245, (2009). http://dx.doi.org/10.1016/j.ergon.2008.08.007

21 Eaton, S. Bus Drivers \& Human Vibration Report, (2003).

${ }^{22}$ Goglia, V., Gospodarić, Z., Kosutić, S., and Filipović, D. Hand-transmitted vibration from the steering wheel to drivers of a small four-wheel drive tractor, Applied Ergonomics, 34, 45-49, (2003). http://dx.doi.org/10.1016/s0003-6870(02)00076-5

23 Aziz, S. A. A., Nuawi, M. Z., Nor, M. J. M., and Daruis, D. D. I. Determination of dominant axis for Hand Arm Vibration (HAV) in Malaysian Army (MA) three-tonne truck steering wheels, Australian Journal of Basic and Applied Sciences, 8 (19), 14-16, (2014).

${ }^{24}$ Shibata, N., Hosoya, N., and Maeda, S. Establishment of one-axis vibration test system for measurement of biodynamic response of human hand-arm system, Industrial Health, 46 (6), 629-634, (2008). http://dx.doi.org/10.2486/indhealth.46.629

25 Giacomin, J. and Woo, Y. J. A study of the human ability to detect road surface type on the basis of steering wheel vibration feedback, Proceedings of the Institution of Mechanical Engineers, Part D: Journal of Automobile Engineering, 219 (11), 1259-1270, (2005). http://dx.doi.org/10.1243/095440705x34955

26 Jena, D. P. and Panigrahi, S. N. Gear fault diagnosis using bispectrum analysis of active noise cancellation-based filtered sound and vibration signals, International Journal of Acoustics and Vibration, 18 (2), 58-70, (2013).

27 Nuawi, M. Z., Nor, M. J. M., Jamaludin, N., Abdullah, S., Lamin, F., and Nizwan, C. K. E. Development of Integrated Kurtosis-Based Algorithm for Z-Filter Technique, Journal of Applied Sciences, 8 (8), 1541-1547, (2008). http://dx.doi.org/10.3923/jas.2008.1541.1547

${ }^{28} \mathrm{Au}, \mathrm{W} . \mathrm{W} . \mathrm{L}$. and Hastings, M. C. Principles of Marine Bioacoustics, Springer, (2009). http://dx.doi.org/10.1111/j.1748-7692.2009.00303.x

${ }^{29}$ Figliola, R. S. and Beasley, D. E. Theory and Design for Mechanical Measurements, 5th edition, John Wiley \& Sons, Inc., (2010).

30 Daubechies, I. Ten Lectures on Wavelets, SIAM, Philadelphia, (1992). http://dx.doi.org/10.1137/1.9781611970104

${ }^{31}$ Ghani, J. A., Rizal, M., Sayuti, A., Nuawi, M. Z., Ramli, R., Deros, B., Hassan, C., and Haron, C. Online tool wear monitoring using portable digital assistant (PDA), International Journal of the Pyhsical Sciences, 6 (16), 4064-4069, (2011).
32 Abdullah, S., Ismail, N., Nuawi, M. Z., Nopiah, M. Z., and Ariffin, A. Using the hybrid Kurtosis-based Method to correlate strain and vibration signals, WSEAS Transactions on Signal Processing, 6 (3), 79-90, (2010).

33 Abdullah, S., Ismail, N., Nuawi, M. Z., Nopiah, M. Z., and Ariffin, A. Study on Correlation between strain and vibration signal using hybrid I-kaz method, Proceedings of the 8th WSEAS International Conference on Signal Processing, Robotics, and Automation (ISPRA), 79-88, (2010).

${ }^{34}$ Karim, Z., Nuawi, M. Z., Md Said, A. Y., Ghani, J. A., and Abdullah, S. I-kaz multilevel coefficients response towards the simultaneous changes in amplitude and frequency of signals, Journal of Applied Sciences, 13 (2), 232-241, (2013). http://dx.doi.org/10.3923/jas.2013.232.241

35 Karim, Z., Nuawi, M. Z., Ghani, J. A., Azrulhisham, E. A., and Abdullah, S. Development of machining condition monitoring system using piezoelectric sensor analyzed by I-kaz multilevel method, World Applied Sciences Journal, 21 (2), 264-268, (2013).

36 Piaw, C. Y. Asas Statistik Penyelidikan, McGraw Hill (Malaysia) Sdn Bhd, Kuala Lumpur, (2012).

37 ISO 5349-2, Mechanical vibration-Measurement and evaluation of human exposure to handtransmitted vibration-Part 2: practical guidance for measurement at the workplace, (2001). http://dx.doi.org/10.3403/02497418u

38 Laws of Malaysia, Act 333 Road Transport Act 1987, (2006).

${ }^{39}$ Gnanasekaran, S., Ajovalasit, M., and Giacomin, J. Driver estimation of steering wheel vibration intensity: laboratorybased tests, Engineering Integrity, 20, 25-31, (2006).

${ }^{40}$ Chaturvedi, V., Kumar, A., and Singh, J. K. Power tiller: Vibration magnitudes and intervention development for vibration reduction, Applied Ergonomics, 43 (5), 891-901, (2012). http://dx.doi.org/10.1016/j.apergo.2011.12.012

${ }^{41}$ Directive 2002/44/EC, Minimum health and safety requirements regarding the exposure of workers to the risks arising from physical agents (vibration), Brussels, (2002). http://dx.doi.org/10.1260/095745602760044939

${ }^{42}$ Sen, Z., Altunkaynak, A., and Ozger, M. Space-time interpolation by combining air pollution and meteorologic variables, Pure and Applied Geophysics, 163, 1435-1451, (2006). http://dx.doi.org/10.1007/s00024-006-0072-8 